\title{
Faktor-Faktor Yang Mempengaruhi Motivasi Bidan Pelaksana Dalam Pelayanan Ibu Nifas Di Wilayah Kabupaten Blora
}

\section{Factors Influencing Motivation of Midwives in Providing Maternal Services in Blora District}

\author{
Epi Saptaningrum ${ }^{1}$, Sutopo Patria Jati ${ }^{2}$, Anneke Suparwati ${ }^{2}$ \\ 1) Poltekkes Kemenkes Semarang, Prodi Keperawatan Blora, email: epiblora@gmail.com \\ 2) Fakultas Kesehatan Masyarakat, Universitas Diponegoro, Semarang
}

\begin{abstract}
Abstrak
Angka Kematian Ibu terbanyak terjadi di masa nifas. Bidan sangat berperan dan bertanggungjawab dalam pelaksanaan Pelayanan Ibu Nifas. Pelaksanaan pelayanan di masa nifas di Kabupaten Blora masih belum optimal. Hal tersebut dipengaruhi oleh motivasi bidan dalam melaksanakan Pelayanan Ibu Nifas. Ada 5 bidan dari 7 bidan yang mengatakan malas dalam melakukan Pelayanan Ibu Nifas khususnya dalam melakukan kunjungan ibu nifas. Motivasi dipengaruhi oleh faktor intrinsik dan faktor ekstrinsik. Untuk mengetahui faktor-faktor yang mempengaruhi motivasi bidan pelaksana dalam Pelayanan Ibu Nifas perlu dilakukan kajian dan penelitian.

Jenis penelitian ini adalah kuantitatif bersifat analitik. Pengambilan data secara cross sectional. Metode pengumpulan data dengan menggunakan kuesioner. Populasi penelitian ini adalah bidan pelaksana di Kabupaten Blora sejumlah 359 bidan. Sampel penelitian berjumlah 76 responden. Sampel dihitung dengan minimal sample size. Uji validitas menggunakan analisis product moment dari pearson. Uji reliabilitas menggunakan koefisien alpha cronbach. Teknik analisis data dengan uji univariat (uji kolmogorov smirnov), uji bivariat (uji chi-square), uji multivariat (uji regresi logistic).

Hasil penelitian menunjukkan bahwa ada hubungan antara persepsi administrasi dan kebijakan dengan motivasi bidan ( $\mathrm{p}=0,043 ; \mathrm{C}=0,227)$, ada hubungan antara persepsi supervisi dengan motivasi bidan $(\mathrm{p}=0,001 ; \mathrm{C}=0,346)$, ada hubungan antara persepsi Pekerjaan Itu Sendiri dengan motivasi bidan $(\mathrm{p}=0,000 ; \mathrm{C}=0,503)$ dan ada hubungan antara persepsi kondisi lingkungan dengan motivasi bidan $(\mathrm{p}=0,001 ; \mathrm{C}=0,350)$. Adapun dari keempat faktor tersebut yang berpengaruh terhadap motivasi adalah faktor persepsi Pekerjaan Itu Sendiri $(\mathrm{p}=0,000)$ dengan nilai ExpB adalah 11,655.

Penelitian ini merekomendasikan beberapa saran yaitu bagi kantor peneliti lain agar meneliti lebih dalam tentang faktor pekerjaan itu sendiri, bagi Dinas Kesehatan agar meninjau kembali tugas pokok dan tambahan terkait dengan beban kerja bidan yang dirasa berat dengan tugastugas tambahan serta mempertimbangkan menaikkan insentif untuk kegiatan pelayanan ibu nifas, bagi IBI Blora agar membina dan meningkatkan motivasi bidan terkait dengan pelayanan masa nifas, bagi Puskesmas (Bidan Kordinator) agar mengikutsertakan bidan pelaksana dalam upaya meningkatkan persepsi tentang pekerjaan itu sendiri (pelayanan masa nifas) melalui pelatihan.
\end{abstract}

Kata kunci : Motivasi, Bidan, Pelayanan Ibu Nifas

Referensi : 17 (2004-2014)

\section{Abstract}

Maternal Mortality Rate mostly occurred during postnatal period. Midwives played an important role and had responsibility in providing maternal services. Postnatal services in Blora 
District had not been optimally implemented. This condition was influenced by motivation of midwives in providing postnatal services. Five of seven midwives said that they were lazy to provide postnatal services particularly in visiting maternal. Motivation was influenced by intrinsic and extrinsic factors. Therefore, factors influencing motivation of midwives in providing maternal services needed to be investigated.

This was a quantitative-analytic study using cross sectional approach. Data were collected using a questionnaire. Number of population was 359 midwives in Blora District. Number of samples were 76 respondents calculated using minimal sample size. A validity test used pearson product moment whereas alpha Cronbach test was used to analyse reliability. Data were analysed using methods of univariate (Kolmogorov-Smirnov test), bivariate (Chi-Square test), and multivariate (logistic regression test).

The results of this research showed that factors of perception of administration and policy $(p=0.043 ; C=0.227)$, perception of supervision $(p=0.001 ; C=0.346)$, perception of work $(p=0.000 ; C=0.503)$ and perception of environmental condition $(p=0.001 ; C=0.350)$ statistically significantly related to motivation of midwives. Perception of work was the most influenced factor of motivation ( $p=0.000 ; \operatorname{Exp}(B)=11.655)$.

As suggestions, other researchers need to investigate the factor of perception of work. District Health Office needs to evaluate main and additional tasks and to consider increasing incentive for activities of maternal services. Indonesian Midwives Association of Blora needs to guide and to improve motivation of midwives in providing maternal services. Health Centres (Coordinator Midwives) need to involve midwives in improving perception of work (maternal services) by conducting training.

Keywords : Motivation, Midwives, Maternal Postpartum Care

Bibliography : 17 (2004-2014)

\section{Pendahuluan}

Angka Kematian Ibu (AKI) di Indonesia berdasarkan SDKI di tahun 2012 adalah 359 per 100.000 kelahiran hidup. AKI tersebut masih cukup jauh dari target MDGs pada tahun 2015 yaitu diharapkan dapat ditekan menjadi 102 per 100.000 kelahiran hidup.

AKI Provinsi Jawa Tengah tahun 2012 sebesar 116,34 per 100.000 kelahiran hidup. Kejadian kematian maternal paling banyak adalah pada waktu nifas yaitu sebesar $57,93 \%$. Kemudian pada waktu hamil sebesar $24,74 \%$, dan pada waktu persalinan sebesar $17,33 \%$. $^{1}$

AKI di Kabupaten Blora mengalami naik turun pada lima tahun terakhir ini. AKI pada tahun 2009 sejumlah 22 kasus $(158,47 / 100.000 \mathrm{kh})$, tahun 2010 hanya 12 kasus $(86,44 / 100.000 \mathrm{kh})$, tahun 2011 sebesar 22 kasus $(164,5 / 100.000 \mathrm{kh})$, tahun 2012 sejumlah 15 kasus $(115,5 / 100.000 \mathrm{kh})$, dan tahun 2013 sejumlah 14 kasus $(119 / 100.000 \mathrm{kh}){ }^{2}$

Berdasarkan profil kesehatan Kabupaten Blora, cakupan pelayanan pada ibu nifas tahun 2009 adalah 92,83\%, tahun 2010 yaitu $89,95 \%$, tahun 2011 adalah 95\%, tahun 2012 adalah 98,4\%, dan di bawah target SPM yaitu $100 \%$. Walaupun cakupan pelayanan ibu nifas sudah bagus, namun kejadian kematian ibu di masa nifas di Kabupaten Blora cukup mencengangkan.

AKI di Kabupaten Blora terbanyak terjadi pada masa nifas yaitu mulai dari tahun 2009 sebesar 59\%. Kemudian tahun 2010 sebesar 91,6\%. Tahun 2011 walaupun sudah menurun angka kematian ibu nifas yaitu sebesar 18,2\% namun berarti masih ada kasus kematian di masa nifas. Tahun 2012 AKI di masa nifas meningkat lagi sebesar 53,3\%. Tahun 2013 AKI di masa nifas meningkat lagi menjadi $57,1 \% .^{3}$

Bidan dalam melakukan pelayanan antenatal dan pertolongan persalinan tidak terdapat kendala yang berarti. Mereka bisa melaksanakan pelayanan antenatal care dan pertolongan persalinan sesuai standar pelayanan. Hal ini dapat dilihat dari hasil cakupan Kunjungan Ibu Hamil yaitu K1 100\% dan K4 96,29\%. Pertolongan persalinan banyak ditolong oleh tenaga kesehatan yaitu mencapai 99,45\%. Dukungan berupa supervisi dan pelatihan tentang pelayanan antenatal dan 
pertolongan sering diadakan. Berbeda dengan pelayanan masa nifas, tidak pernah ada pelatihan sejenis.

Hasil prasurvey di Dinas Kesehatan Kabupaten Blora telah mensosialisasikan Standar Pelayanan Nifas yang terdiri dari 3 standar yaitu Standar perawatan Bayi Baru Lahir, Standar penanganan pada dua jam pertama persalinan, dan Standar Pelayanan bagi ibu dan bayi pada masa nifas, yang di dalamnya terdapat kunjungan ibu nifas di rumah. Supervisi dilakukan oleh Dinas Kesehatan setiap 6 (enam) bulan sekali yaitu supervisi program KIA termasuk Kunjungan Nifas, namun belum pernah dilakukan supervisi langsung ke desa dalam program pelayanan ibu nifas atau kunjungan ibu nifas. Selain itu, belum ada SK (Surat Keputusan) dari Bupati tentang pelaksanaan Pelayanan Ibu Nifas. Sehingga kegiatan kunjungan ibu nifas ini mengikuti program dari Kemenkes yang tertuang dalam buku PWSKIA.

Studi pendahuluan pada bidan di dua puskesmas wilayah kerja Kabupaten Blora didapatkan data hasil interview bahwa terjadi kecenderungan pelayanan ibu nifas oleh bidan belum optimal, misalnya kunjungan ibu nifas hanya dilakukan satu kali yaitu saat hari keenam. Dan saat diklarifikasi ke pasien, ternyata enam dari delapan pasien mengatakan bahwa ibu bidan melakukan kunjungan ke rumah pada hari keenam saja. Yang dilakukan bidan saat kunjungan ibu nifas adalah melakukan pemeriksaan tekanan darah, memeriksa keadaan bayi, dan memberikan obat serta menyarankan untuk kontrol. Bidan cenderung tidak melakukan kunjungan nifas pada dua minggu post partum dan enam minggu post partum karena pasien disuruh kontrol ke tempat bidan praktek. Hal ini tidak sesuai dengan program Kemenkes yang mewajibkan bidan untuk melakukan kunjungan nifas sebanyak 3 (tiga) kali. Padahal dari kunjungan ibu nifas inilah bidan menjadi lebih tahu tentang keadaan klien yang sebenarnya misal tentang makanan sehari-hari yang dikonsumsi, pantang makan yang dilakukan ataupun komplikasi persalinan yang dialami klien.

Alasan yang disampaikan oleh bidan dengan hal tersebut karena kondisi ibu sudah bagus, pasien disuruh datang ke rumah bidan sehingga tidak perlu kunjungan rumah lagi. Selain itu bidan enggan mengunjungi berkalikali ke rumah pasien yang jauh, bisa menghemat tenaga dan waktu untuk melakukan kegiatan yang lain. Hasil interview pada 7 (tujuh) bidan, 5 (lima) bidan mengatakan bahwa kadang ada rasa malas untuk melakukan kunjungan nifas. Rasa malas tersebut disebabkan karena jalan yang jelek dan rusak, dan karena sedikitnya jumlah pasien post partum yang dikunjungi. Selain itu, supervisi dilakukan oleh Dinas Kesehatan Kabupaten setiap 6 (enam) bulan sekali ke Puskesmas, namun tidak pernah kunjungan langsung ke desa sehingga bidan cenderung merasa tidak terawasi dalam pelaksanaan kunjungan ibu nifas. Bidan menyadari pentingnya kunjungan nifas yang bisa mendeteksi komplikasi nifas secara dini, namun banyak laporan dan pekerjaan lain yang harus mereka lakukan membuat mereka malas melakukan kunjungan nifas sesuai standar.

Faktor yang berpengaruh terhadap motivasi ada dua yaitu faktor intrinsik dan faktor ekstrinsik. Faktor intrinsik meliputi pencapaian prestasi, pengakuan, pekerjaan itu sendiri, tanggung jawab, dan pengembangan potensi individu. Sedangkan faktor ekstrinsik meliputi administrasi kebijakan, supervisi, kondisi kerja, dan hubungan interpersonal. ${ }^{4}$

Salah satu upaya untuk menurunkan angka kematian ibu dan angka kematian bayi adalah pelayanan ibu nifas yang berkualitas. Pelayanan yang berkualitas itu sendiri diwujudkan dengan melakukan pelayanan yang sesuai standar. Di sinilah motivasi diperlukan bagi bidan agar pelayanan ibu nifas yang dilakukan bisa berkualitas dan sesuai standar.

\section{Metode Penelitian}

Jenis penelitian observasional analitik dengan pendekatan Cross Sectional. Populasi penelitian adalah bidan pelaksana di Kabupaten Blora sebanyak 359. Cara pengambilan sampel dengan tehnik Proporsional Random Sampling. Jumlah sampel 76 responden. Variabel bebas adalah persepsi administrasi dan kebijakan, persepsi supervisi, persepsi kondisi lingkungan kerja dan persepsi pekerjaan itu sendiri (pelayanan ibu nifas). Variabel terikat adalah motivasi 
bidan pelaksana dalam pelayanan ibu nifas. Pengumpulan data menggunakan angket terstruktur. Analisis data menggunakan analisis univariat (distribusi frekuensi), analisis bivariat (uji chi-square) dan analisis multivariate dengan Regresi Logistik.

\section{Hasil}

Hasil penelitian menunjukkan bahwa 64 responden $(84,2 \%)$ dalam rentang usia dewasa dan 12 responden $(15,8 \%)$ dalam rentang tua.73 responden $(96,1 \%)$ sudah menikah dan 3 responden $(3,9 \%)$ dalam belum kawin. 62 responden $(81,6 \%)$ mempunyai pendidikan D3 dan 14 responden $(18,4 \%)$ berpendidikan D4. Sehingga dalam hal ini sebagian besar pemberi pelayanan ibu nifas terbanyak adalah berpendidikan DIII Bidan. 10 responden $(13,2 \%)$ adalah bermasa kerja baru $(<5$ tahun) dan 66 responden $(86,8 \%)$ mempunyai masa kerja yang lama ( $>5$ tahun).

Hasil analisis uji univariat menujukkan bahwa sebagian besar bidan pelaksana 52,6\% memiliki motivasi rendah dalam pelayanan ibu nifas seperti terlihat dalam tabel 1 .

Tabel 1. Kategori Motivasi Bidan dalam Pelayanan Ibu nifas di wilayah Kabupaten Blora tahun 2014

\begin{tabular}{cccc}
\hline No & Motivasi & $\mathrm{N}$ & $\%$ \\
\hline 1 & Motivasi Rendah & 40 & 52,6 \\
2 & Motivasi Tinggi & 36 & 47,4 \\
\hline & Jumlah & 76 & 100 \\
\hline
\end{tabular}

Tabel 1 tersebut diatas menunjukkan bahwa 40 responden $(52,6 \%)$ memiliki motivasi yang rendah dan 36 responden $(47,4$ $\%)$ mempunyai motivasi yang tinggi dalam pelayanan ibu nifas di Kabupaten Blora. Jadi data tersebut menunjukkan bahwa bidan yang mempunyai motivasi tinggi $(47,4 \%)$ lebih kecil daripada bidan yang mempunyai motivasi rendah $(52,6 \%)$.

Motivasi adalah keinginan yang terdapat pada diri seseorang individu yang merangsangnya untuk melakukan tindakan tindakan. Motivasi itu tampak dalam dua segi yang berbeda. Dari segi aktif/dinamis motivasi tampak sebagai suatu usaha yang positif dalam menggerakkan, mengerahkan, dan mengarahkan daya serta potensi kerja, agar secara produktif berhasil mencapai dan mewujudkan tujuan yang ditetapkan sebelumnya. Dari segi pasif/statis motivasi akan tampak sebagai kebutuhan sekaligus sebagai perangsang untuk dapat menggerakkan, mengerahkan, dan mengarahkan daya serta potensi kerja manusia tersebut kearah yang diinginkan. ${ }^{4}$

Pendapat Sri Hidayati bahwa motivasi merupakan kekuatan-kekuatan yang ada dalam diri seseorang yang memulai dan mengarahkan perilaku atau tindakan tertentu. Perilaku yang bersemangat adalah hasil dari motivasi yang kuat.

Sebagian besar bidan pelaksana memiliki persepsi administrasi dan kebijakan yang baik $(72,4 \%)$ seperti yang tampak dalam tabel 2 .

Tabel 2. Kategori Persepsi Administrasi dan Kebijakan Bidan Pelaksana dalam Pelayanan Ibu nifas di wilayah Kabupaten Blora Tahun 2014

\begin{tabular}{cccc}
\hline No & $\begin{array}{c}\text { Persepsi Administrasi dan } \\
\text { Kebijakan }\end{array}$ & $\mathrm{N}$ & $\%$ \\
\hline 1 & Kurang Baik & 21 & 27,6 \\
2 & Baik & 55 & 72,4 \\
\hline \multicolumn{2}{c}{ Jumlah } & 76 & 100 \\
\hline
\end{tabular}

Tabel 2 diatas menunjukkan bahwa 21 responden $(27,6 \%)$ memiliki persepsi yang kurang baik terhadap administrasi dan kebijakan dan 55 responden $(72,4 \%)$ mempunyai persepsi yang baik terhadap administrasi dan kebijakan dalam pelayanan ibu nifas di Kabupaten Blora.

Tabel 3. Kategori persepsi kondisi lingkungan kerja bidan pelaksana dalam pelayanan ibu nifas di Wilayah Kabupaten Blora Tahun 2014

\begin{tabular}{clcc}
\hline No & $\begin{array}{c}\text { Persepsi Kondisi } \\
\text { Lingkungan Kerja }\end{array}$ & N & $\%$ \\
\hline 1 & Kurang Baik & 27 & 35.5 \\
2 & Baik & 49 & 64.5 \\
\hline & Jumlah & 76 & 100 \\
\hline
\end{tabular}

Tabel 3 diatas menunjukkan bahwa 27 responden $(35,5 \%)$ memiliki persepsi yang kurang baik terhadap kondisi lingkungan kerja dan 49 responden $(64,5 \%)$ mempunyai persepsi yang baik terhadap kondisi lingkungan kerja dalam pelayanan ibu nifas di Kabupaten Blora. Sehingga sebagian besar persepsi kondisi lingkungan kerja bidan 
pelaksana dalam pelayanan ibu nifas di Kabupaten Blora adalah baik (64,5\%).

Tabel 4. Kategori persepsi supervisi bidan pelaksana dalam pelayanan ibu nifas di wilayah Kabupaten Blora di tahun 2014

\begin{tabular}{clcc}
\hline No & Persepsi supervisi & N & $\%$ \\
\hline 1 & Kurang Baik & 38 & 50 \\
2 & Baik & 38 & 50 \\
\hline \multicolumn{2}{c}{ Jumlah } & 76 & 100 \\
\hline
\end{tabular}

Tabel 4 menunjukkan bahwa 38 responden $(50,0 \%)$ memiliki persepsi yang kurang baik terhadap supervisi dan 38 responden $(50,0 \%)$ mempunyai persepsi yang baik terhadap supervisi dalam pelayanan ibu nifas di wilayah Kabupaten Blora. Sehingga persepsi supervisi bidan pelaksana dalam pelayanan ibu nifas di wilayah Kabupaten Blora adalah seimbang antara yang kurang baik dan baik yaitu sama-sama 50\%.

Tabel 5. Kategori persepsi pekerjaan itu sendiri bidan dalam pelayanan Ibu nifas di wilayah Kabupaten Blora tahun 2014

\begin{tabular}{clcc}
\hline No & $\begin{array}{c}\text { Persepsi Pekerjaan Itu } \\
\text { Sendiri }\end{array}$ & N & $\%$ \\
\hline 1 & Kurang Baik & 46 & 60,5 \\
2 & Baik & 30 & 39,5 \\
\hline \multicolumn{2}{c}{ Jumlah } & 76 & 100 \\
\hline
\end{tabular}

Tabel 5 menunjukkan bahwa 46 responden $(60,5 \%)$ memiliki persepsi yang kurang baik terhadap pekerjaan itu sendiri dan 30 responden $(39,5 \%)$ mempunyai persepsi yang baik terhadap kondisi lingkungan dalam pelayanan ibu nifas di Kabupaten Blora. Sehingga persepsi pekerjaan itu sendiri dalam pelayanan ibu nifas di wilayah Kabupaten Blora terbanyak adalah kurang baik $(60,5 \%)$.

Hasil distribusi menunjukkan $89,7 \%$ bidan menyatakan bahwa melalui kunjungan ke rumah pada pelayanan ibu nifas bidan bisa melihat perilaku pasien dan keluarga yang tidak sesuai dengan kesehatan, dan $21 \%$ bidan menyatakan bahwa melaksanakan kunjungan ke rumah sebanyak 3 kali menjadi beban berat.

Tabel 6. Kategori Pengetahuan Bidan dalam Pelayanan Ibu nifas di wilayah Kabupaten Blora Tahun 2014

\begin{tabular}{clcc}
\hline No & \multicolumn{1}{c}{ Pengetahuan } & N & $\%$ \\
\hline 1 & Kurang & 19 & 25 \\
2 & Baik & 57 & 75 \\
\hline \multicolumn{2}{c}{ Jumlah } & 76 & 100 \\
\hline
\end{tabular}

Tabel 6 menunjukkan bahwa 19 responden $(25,0 \%)$ memiliki pengetahuan yang kurang dan 57 responden $(75,0 \%)$ mempunyai pengetahuan yang baik dalam pelayanan ibu nifas di Kabupaten Blora. Sehingga pengetahuan reponden terbanyak adalah baik $(75,0 \%)$.

Hasil distribusi menunjukkan bahwa 90,8\% bidan tahu tentang pengertian nifas, sebanyak $84,2 \%$ bidan tahu tentang tujuan pengelolaan nifas dan $84,2 \%$ bidan tahu tentang hal yang perlu dilakukan saat kunjungan rumah, pemeriksaan kesehatan saat kunjungan nifas. Namun ada 23,7\% bidan tidak tahu hal-hal yang perlu dilakukan pada ibu nifas dan pernyataan yang benar tentang kunjungan ibu nifas. Ketidaktahuan bidan tentang kedua hal tersebut, bukan tidak mungkin akan membuat bidan merasa malas dan tidak mau melakukan kegiatan kunjungan ibu nifas.

Hasil Analisis Bivariat dengan menggunakan uji Chi Square didapatkan hasil adanya hubungan antara persepsi administrasi dan kebijakan dengan motivasi bidan, ada hubungan antara persepsi kondisi lingkungan kerja dengan motivasi bidan, ada hubungan antara persepsi supervisi dengan motivasi bidan . Hasil Analis Hubungan Variabel bebas dengan Variabel Terikat dengan uji Chi Square pada $\alpha 5 \%$. $^{12}$

Tabel 7. Hubungan administrasi kebijakan dengan motivasi bidan dalam pelayanan ibu nifas di wilayah Kabupaten Blora tahun 2014

\begin{tabular}{llcccccc}
\hline \multirow{2}{*}{ No } & Adminitrasi dan Kebijakan & \multicolumn{6}{c}{ Motivasi } \\
\cline { 3 - 8 } & & \multicolumn{2}{c}{ Rendah } & \multicolumn{2}{c}{ Tinggi } & \multicolumn{2}{c}{ Total } \\
\cline { 2 - 8 } & $\mathrm{N}$ & $\%$ & $\mathrm{~N}$ & $\%$ & $\mathrm{~N}$ & $\%$ \\
\hline 1. & Kurang Baik & 15 & 71,4 & 6 & 28,6 & 21 & 100 \\
2. & Baik & 25 & 45,58 & 30 & 54,5 & 55 & 100 \\
\hline $\mathrm{x}^{2}: 4,113 ; \mathrm{p}=0,043 ; \mathrm{C}=0,227$ & & & & &
\end{tabular}


Tabel diatas tampak bahwa bidan yang memiliki motivasi rendah cenderung memiliki persepsi administrasi kebijakan yang kurang baik, dan sebaliknya bidan yang memiliki motivasi yang tinggi cenderung memiliki persepsi administrasi kebijakan yang baik.

Hasil Chi Square antara Administrasi dan Kebijakan dengan motivasi bidan pelaksana dalam pelayanan ibu nifas menunjukkan nilai $\mathrm{p}=0,043 \quad(\mathrm{p}<0,05)$, dan nilai koefisien kontingensi $(\mathrm{C})=0,227$. Hasil ini memiliki makna ada hubungan yang signifikan antara administrasi dan Kebijakan dengan motivasi bidan pelaksana dalam pelayanan ibu nifas.

Tabel 8. Hubungan supervisi dengan motivasi bidan dalam pelayanan ibu nifas di wilayah Kabupaten Blora tahun 2014

\begin{tabular}{llcccccc}
\hline \multirow{2}{*}{ No } & \multirow{9}{*}{ Supervisi } & \multicolumn{9}{c}{ Motivasi } \\
\cline { 3 - 8 } & & \multicolumn{2}{c}{ Rendah } & \multicolumn{2}{c}{ Tinggi } & \multicolumn{2}{c}{ Total } \\
\cline { 2 - 7 } & $\mathrm{N}$ & $\%$ & $\mathrm{~N}$ & $\%$ & $\mathrm{~N}$ & $\%$ \\
\hline 1. & Kurang baik & 27 & 71,1 & 11 & 28,9 & 38 & 100 \\
2. & Baik & 13 & 34,2 & 25 & 65,8 & 38 & 100 \\
\hline $\mathrm{x}^{2}=10,344 ; \mathrm{p}=0,001 ; \mathrm{C}=0,346$ & & & & &
\end{tabular}

Tabel silang diatas tampak bahwa bidan yang memiliki motivasi rendah cenderung memiliki persepsi supervisi yang kurang baik, dan sebaliknya bidan yang memiliki motivasi yang tinggi cenderung memiliki persepsi supervisi yang baik.

Hasil chi-square antara Supervisi dan motivasi bidan praktek mandiri dalam penerapan pencegahan infeksi menunjukkan $x^{2}=10,344$ dan nilai $\mathrm{p}=0,001(\mathrm{p}<0,05)$, dan nilai koefisien kontingensi $(\mathrm{C})=0,346$. Hasil ini memiliki makna ada hubungan yang signifikan antara persepsi Supervisi dengan motivasi bidan pelaksana dalam pelayanan ibu nifas.

Tabel 9. Hubungan pekerjaan itu sendiri dengan motivasi bidan dalam pelayanan ibu nifas di wilayah Kabupaten Blora tahun 2014

\begin{tabular}{clcccccc}
\hline \multirow{2}{*}{ No } & Pekerjaan Itu Sendiri & \multicolumn{6}{c}{ Motivasi } \\
\cline { 3 - 8 } & (Pelayanan Ibu Nifas) & \multicolumn{2}{c}{ Rendah } & \multicolumn{2}{c}{ Tinggi } & \multicolumn{2}{c}{ Total } \\
\cline { 2 - 8 } & & $\mathrm{N}$ & $\%$ & $\mathrm{n}$ & $\%$ & $\mathrm{~N}$ & $\%$ \\
\hline 1. & Kurang baik & 35 & 76.1 & 11 & 23,9 & 46 & 100 \\
2. & Baik & 5 & 16,7 & 25 & 83,3 & 30 & 100 \\
\hline $\mathrm{x}^{2}=25,716 ; \mathrm{p}=0,000 ; \mathrm{C}=0,503$ & & & & & & &
\end{tabular}

Tabel silang diatas tampak bahwa bidan yang memiliki motivasi rendah cenderung memiliki persepsi pekerjaan itu sendiri kurang baik, dan sebaliknya bidan yang memiliki motivasi yang tinggi cenderung memiliki persepsi pekerjaan itu sendiri baik.

Hasil Chi Square antara Pekerjaan Itu Sendiri dan motivasi bidan pelaksana dalam pelayanan ibu nifas menunjukkan $x^{2}=25,716$ dan nilai $p=0,000(p<0,05)$ dengan nilai ko efisien kontingensi $(\mathrm{C})=0,503$. Hasil ini memiliki makna ada hubungan yang signifikan antara Pekerjaan Itu Sendiri dengan motivasi bidan dalam pelayanan ibu nifas. ${ }^{10,12}$

Tabel 10. Hubungan kondisi lingkungan dengan motivasi bidan dalam pelayanan Ibu nifas di wilayah Kabupaten Blora tahun 2014

\begin{tabular}{cccccccc}
\hline \multirow{2}{*}{ No } & \multirow{2}{*}{ Kondisi Lingkungan } & \multicolumn{9}{c}{ Motivasi } \\
\cline { 3 - 8 } & & \multicolumn{2}{c}{ Rendah } & \multicolumn{2}{c}{ Tinggi } & \multicolumn{2}{c}{ Total } \\
\cline { 2 - 8 } & $\mathrm{N}$ & $\%$ & $\mathrm{n}$ & $\%$ & $\mathrm{~N}$ & $\%$ \\
\hline 1. & Kurang Baik & 21 & 77,8 & 5 & 22,2 & 27 & 100 \\
2. & Baik & 19 & 38,8 & 30 & 61,2 & 49 & 100 \\
\hline $\mathrm{x}^{2}=10,622 ; \mathrm{p}=0,001 ; \mathrm{C}=0,350$ & & & & & &
\end{tabular}


Tabel silang tersebut terlihat bahwa bidan yang memiliki motivasi rendah cenderung mempersepsikan kondisi lingkungan kerja yang kurang baik, dan sebaliknya bidan yang memiliki motivasi yang tinggi cenderung memiliki persepsi kondisi lingkungan kerja yang baik.

Hasil Chi Square antara persepsi kondisi lingkungan dengan motivasi bidan pelaksana dalam pelayanan ibu nifas menunjukkan $\mathrm{x}^{2}=$
10,622 dan nilai $\mathrm{p}=0,001(\mathrm{p}<0,05)$ dengan nilai koefisien kontingensi $(\mathrm{C})=0,350$. Hasil ini memiliki makna ada hubungan yang signifikan antara persepsi kondisi lingkungan dengan motivasi bidan dalam pelayanan ibu nifas $^{9,12}$.

Uji multivariat yang digunakan yaitu perhitungan uji regresi logistik, setelah dilakukan analisis diperoleh hasil sebagai berikut :

Tabel 11. Hasil analisis multivariat

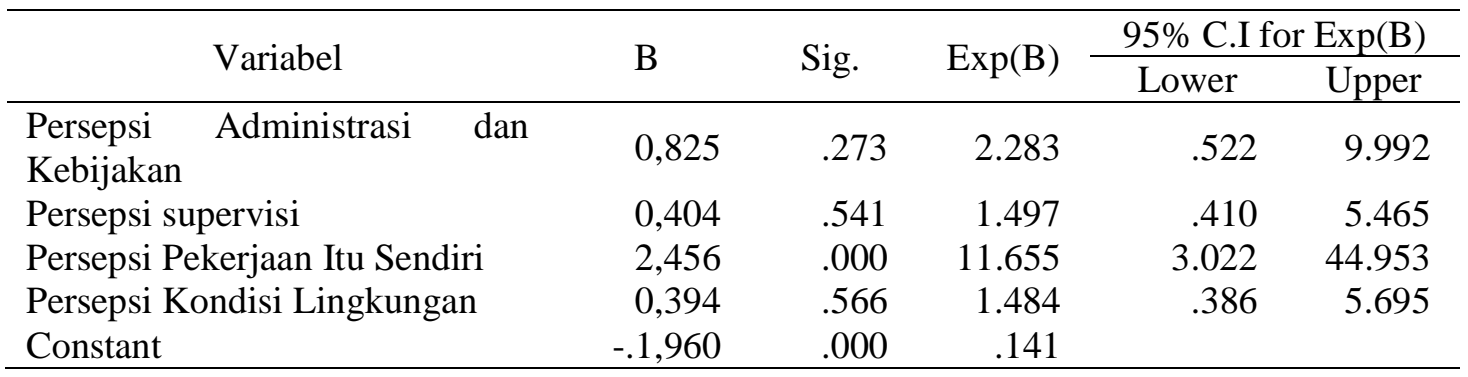

Tabel 11 menunjukkan bahwa variabel yang memiliki nilai signifikansi $\mathrm{p}<0,05$ adalah persepsi pekerjaan itu sendiri dengan nilai $p=0,000$. Hal ini menunjukkan dari empat variabel yang diuji, ternyata variabel yang berpengaruh terhadap motivasi bidan pelaksana dalam pelayanan ibu nifas yaitu variabel persepsi terhadap pekerjaan itu sendiri. Adapun variabel yang lain tidak berpengaruh terhadap motivasi bidan dalam pelayanan ibu nifas.

\section{Pembahasan}

Persepsi administrasi dan kebijakan mempunyai nilai $p=0,043$. Ini berarti bahwa ada hubungan antara persepsi administrasi dan kebijakan dengan motivasi. Hal ini sesuai pendapat Hamzah (2011) menyatakan bahwa administrasi dan kebijakan instansi/organisasi merupakan salah satu wujud umum rencanarencana tetap dari fungsi perencanaan dan kebijakan adalah pedoman umum perbuatan keputusan. Kebijakan merupakan batas bagi keputusan, menentukan apa yang dapat dibuat dan menutup apa yang tidak dapat dibuat. ${ }^{4}$

Persepsi supervisi mempunyai nilai $\mathrm{p}=0,001$. Berarti ada hubungan antara persepsi supervisi dengan motivasi. Pendapat Prabu (2011) bahwa supervisi adalah suatu kegiatan pembinaan, atau pengawasan oleh pengelola program terhadap pelaksana ditingkat administrasi yang lebih rendah dalam rangka menetapkan kegiatan sesuai dengan tujuan dan sasaran yang telah ditetapkan. ${ }^{5}$ Sehingga dengan adanya supervisi diharapkan bawahan termotivasi untuk bekerja lebih giat lagi.

Persepsi pekerjaan itu sendiri mempunyai nilai $\mathrm{p}=0,000$. Berarti ada hubungan antara persepsi pekerjaan itu sendiri dengan motivasi. ${ }^{6}$ Pekerjaan itu sendiri merupakan suatu pertimbangan yang sangat penting dalam motivasi. Sesuai teori Herzberg yang menyatakan pekerjaan yang diberikan kepada karyawan menentukan sikap karyawan tentang pekerjaan yang mereka lakukan. ${ }^{7}$ Dengan demikian dengan persepsi terhadap pekerjaan baik maka akan meningkatkan motivasi.

Persepsi kondisi lingkungan mempunyai nilai $\mathrm{p}=0,001$. Berarti ada hubungan antara kondisi lingkungan kerja dengan motivasi. Teori Herzberg mengatakan bahwa: "Kondisi kerja yang merupakan faktor yang dapat menimbulkan ketidakpuasan dimana jika kondisi kerja yang kondusif dan memadai maka akan cenderung meningkatkan motivasi kerja karyawan". Sehingga kondisi kerja merupakan salah satu faktor strategis yang dapat mempengaruhi motivasi karyawan. ${ }^{8}$

Sesuai pendapat Bond, dkk (2004) dan Wade (2007) yaitu aspek lingkungan kerja seringkali dapat meningkatkan motivasi, kepuasan dalam bekerja dan mengurangi kelemahan emosional antara perusahaan dan organisasi. Kondisi kerja (meliputi kondisi 
fisik, kondisi psikologis, dan kondisi sementara dari lingkungan kerja) yang diperhatikan dengan baik maka secara otomatis akan mempengaruhi kepada motivasi kerja karyawan itu sendiri karena merasa nyaman dalam bekerja sehingga dapat meningkatkan produktivitas kerja. ${ }^{15}$

Wahyuni (2011) dalam penelitian juga mengungkapkan bahwa kondisi kerja adalah sarana prasarana yang memadai sesuai dengan sifat tugas yang harus diselesaikan. Sarana prasarana yang tersedia hendaknya dalam jumlah serta jenis yang memadai dan lengkap. Tanpa sarana prasarana yang baik seseorang tidak dapat berbuat banyak apalagi meningkatkan produktivitas kerjanya. ${ }^{17}$

Hasil uji multivariat menunjukkan bahwa variabel yang memiliki nilai signifikansi $\mathrm{p}<0,05$ adalah persepsi pekerjaan itu sendiri dengan nilai $\mathrm{p}=0,000$. Hal ini menunjukkan dari empat variabel yang diuji, ternyata variabel yang berpengaruh terhadap motivasi bidan pelaksana dalam pelayanan ibu nifas yaitu variabel persepsi terhadap pekerjaan itu sendiri. Adapun variabel yang lain tidak berpengaruh terhadap motivasi bidan dalam pelayanan ibu nifas. ${ }^{12,13}$

Persepsi terhadap Pekerjaan Itu Sendiri mempunyai $\operatorname{Exp}(\mathrm{B})$ sebesar 11,655 menunjukkan bahwa bidan yang mempunyai persepsi terhadap pekerjaan itu sendiri baik, mempunyai motivasi 11 kali lebih baik dari pada yang mempunyai persepsi terhadap Pekerjaan Itu Sendiri yang buruk. Hal ini menunjukkan bahwa faktor persepsi terhadap pekerjaan itu sendiri memiliki kontribusi besar untuk dapat meningkatkan ataupun menurunkan motivasi bidan dalam pelayanan ibu nifas.

\section{Kesimpulan}

Hanya faktor persepsi pekerjaan itu sendiri yang mempengaruhi motivasi bidan dalam melakukan pelayanan ibu nifas di wilayah Kabupaten Blora (sig= 0,000; Exp $(B)=11,655)$. Faktor persepsi administrasi dan kebijakan (sig. $=0,273)$, faktor persepsi supervisi $(\mathrm{sig}=0,541)$ dan faktor persepsi kondisi lingkungan kerja $(\mathrm{sig}=0,566)$ disimpulkan tidak mempengaruhi motivasi bidan dalam pelayanan ibu nifas di wilayah Kabupaten Blora.

\section{DAFTAR PUSTAKA}

1. Dinas Kesehatan Provinsi Jawa Tengah. Profil Kesehatan Provinsi Jawa Tengah tahun 2012. Semarang: 2012.

2. Dinas Kesehatan Kabupaten Blora. Profil Kesehatan Kabupaten Blora tahun 2012. Blora: 2012.

3. Dinas Kesehatan Kabupaten Blora. Profil Kesehatan Kabupaten Blora tahun 2013. Blora: 2013.

4. Uno, Hamzah B. Teori Motivasi dan Pengukurannya. Jakarta: PT. Bumi Aksara; 2011.

5. Prabu, M.A. Manajemen Sumber Daya Manusia Perusahaan. Bandung: Rosda; 2011.

6. Notoadmodjo. Promosi Ilmu Kesehatan dan Perilaku. Jakarta: Rineka cipta Aksara; 2008.

7. Siagian, SP. Teori Motivasi dan Aplikasinya. Jakarta: PT Rineka Cipta; 2004.

8. Malayu, SP. Hasibuan. Organisasi dan Motivasi. Jakarta: PT Bumi Aksara; 2007.

9. Mitayani. Asuhan Keperawatan Maternitas. Jakarta: Penerbit Salemba Medika; 2009.

10. Regina, Novita. Keperawatan Maternitas. Cetakan 1. Bogor: Penerbit Ghalia Indonesia; 2011.

11. Simatupang, Erna Juliana. Manajemen Pelayanan Kebidanan. Jakarta: EGC; 2008.

12. Suyanto. Riset Kebidanan Metodologi dan Aplikasi. Jakarta: Mitra Cendekia Offset; 2009.

13. Anggoro, M.Toha dkk. Materi Pokok Metode Penelitian. Jakarta: Universitas Terbuka; 2007.

14. Ivancevich, John M. .Perilaku dan Manajemen Organisasi. Jakarta: Penerbit Erlangga: 2006.

15. Hidayati, Sri. Faktor- Faktor yang Berhubungan dengan Kinerja Bidan dalam Pelaksanaan Inisiasi Menyusu Dini di RSUP Dr Kariadi Semarang (Tesis). Semarang: Program Studi Magister Kesehatan Masyarakat Pasca Sarjana Universitas Diponegoro; 2014. 
16. Widyarni, Ari. Evaluasi Faktor Motivasi Pemberian Penyuluhan Kesehatan oleh Petugas Gizi di Pos Pelayanan Terpadu Lanjut Usia (Studi di Puskesmas Kota Banjarbaru tahun 2013) (Tesis). Semarang: Program Studi Magister Kesehatan Masyarakat Pasca Sarjana Universitas Diponegoro; 2013.

17. Wahyuni, Sri. Faktor-faktor yang Mempengaruhi Motivasi Bidan Desa dalam Penggunaan Partograf di Kabupaten Semarang tahun 2011 (Tesis). Semarang: Program Studi Magister Kesehatan Masyarakat Pasca Sarjana Universitas Diponegoro; 2011. 